\title{
Derecho Hodierno: Utilidad del Deductivismo en la Praxis orientada al Ideal Eficaz
}

Hodiernal Right: Deductivism Utility in the Praxis aims to the Efficacious Ideal

\author{
Valeria Freire Yacelga \\ Investigadora Jurídica, TAXFIRM
}

Artículo Original (Revisión)

RFJ, No. 3, 2018, pp. 199-213, ISSN 2588-0837

RESUMEN: a través del documento se identifica si el deductivismo es o no útil en el ejercicio empírico del derecho hodierno, que, pretende alcanzar la mayor eficacia posible. Se determina la relevancia del análisis económico, porque los juristas desarrollan procesos de razonamiento como la deducción, con incidencia de aspectos exógenos como la economía, y su eficacia está ligada a ellos. Se concluye que la deducción es útil en la praxis del derecho hodierno, porque permite contrastar, comparar y extraer esencialidades de toda información sensopercibida, pero, también se requiere de otros recursos racionales que se complementan y proporcionan una noción predictiva e incrementan el nivel de eficacia normativa.

PALABRAS CLAVES: derecho, hodierno, economía, deductivismo, eficacia.

ABSTRACT: through the document, it is identified if the deductivism is useful or not in the empirical exercise of hodiernal right, which aims to achieve the maximum efficacy. It is determined the relevance of economic analysis, in the reason of, jurists develop reasoning processes like deduction, with an incidence of exogenous aspects such as economy, and its effectiveness is linked to those. It is concluded that the deduction is useful in the praxis of hodiernal right, because it allows contrast, compare and extract essentialities of all information, but also requires other rational resources that complement and provide a predictive notion and increase the level of effectiveness normative.

KEY WORDS: hodiernal, right, economy, deductivism, efficacy. 


\section{INTRODUCCIÓN}

Los seres humanos en esencia poseen como caracteres inherentes la conducta y el raciocinio. De esta manera, el derecho hodierno como el cúmulo de normas que regulan la conducta humana hoy en día, y el deductivismo como un método de conocimiento basado en la lógica, son dos aspectos que se complementan en la cotidianidad de los juristas, pues permiten una regulación adecuada, pero sobre todo un desarrollo de las potencialidades críticas humanas, basadas en conceptos y normas que constituyen referentes del "deber ser", pero, que trascienden la mera interpretación textual, debido a que los juristas extraen lo que según su sana crítica consideran adecuado para generar nuevas ideas que pueden llegar a constituir normativa jurídica o fundamentos para argüir la postura propia respecto de un caso, tanto al litigar como al redactar.

El hombre es el producto de la cohesión entre el ámbito psíquico y el aspecto somático, por consiguiente, se desarrollan procesos cognitivos en su mente. Entre el desempeño de actividades basadas en el razonamiento, se encuentra el deductivismo, que constituye una herramienta base para la construcción de ideas y conocimiento. Sin embargo, la deducción se limita a la extracción de esencialidades provistas de premisas previamente planteadas, por lo que resulta necesaria la utilización de otros métodos de conocimiento para poder ejercer de la manera más óptima posible. Entonces, surge la dubitación respecto de ¿El deductivismo es útil o no útil en el ejercicio empírico del Derecho que constantemente pretende alcanzar la mayor eficacia posible?

Consecuentemente, el documento tiene el objetivo de identificar si el deductivismo es o no útil en el ejercicio empírico del derecho que constantemente pretende alcanzar la mayor eficacia posible. Por consiguiente, en la primera sección del trabajo, se identifica la incidencia e importancia de la deducción en la emisión crítica de interpretaciones jurídicas de las normas y en la toma de decisiones por parte de los juristas; en la segunda sección, se determina de la relevancia que presenta el análisis económico en la eficacia jurídica a base de la propuesta de (Fraga, 2016); y en la tercera sección, se establece una relación entre la deducción y la eficiencia en la cotidianeidad de los agentes. 


\section{INCIDENCIA E IMPORTANCIA DE LA DEDUCCIÓN EN LA EMISIÓN DE INTERPRETACIONES JURÍDICAS DE LAS NORMAS Y EN LA TOMA DE DECISIONES POR PARTE DE LOS JURISTAS}

Los juristas, constantemente deben desenvolverse en diversos escenarios jurídicos (físicos), incluidas las salas de audiencia donde acuden a litigar, las oficinas donde deben redactar documentos legales, entre otros. Sin embargo, los escenarios jurídicos, no se reducen al espacio físico en el que desempeñan acciones los agentes de derecho, porque los juristas también se ven expuestos a escenarios hipotéticos que permiten deducir, inferir, comparar, básicamente idealizar una situación determinada que permite al abogado codificar en su mente una noción respecto de una situación de la que no necesariamente fue testigo, pero que le proveerá la base de la cual partirá para ejercer su profesión aplicada en un caso particular.

De este modo, la interpretación crítica de los juristas resulta indispensable al momento de desenvolverse en los distintos escenarios jurídicos, tanto físicos como hipotéticos. Entonces, es ineludible el desarrollo de procesos cognitivos de razonamiento como la deducción, que mediante la percepción de una o más ideas, genera una nueva idea con la pretensión de incrementar el nivel de certeza de la premisa y así poder impartir justicia o promover el acontecimiento de un acto justo.

Igualmente, existen autores que destacan la importancia del deductivismo, no solo en el ámbito jurídico, sino en todas las áreas, en la vida misma, como se evidencia al señalar que:

"Según este paradigma -también llamado de consecuencia deductiva lógica- ha de presentarse una serie de características para que una consecuencia sea efectivamente lógica, como por ejemplo, la monotonía: una deducción es irrefutable pues sus premisas no admiten adición de información" (Cordero, 2009).

Pero, se considera que es antagónico e incluso incoherente indicar que las premisas no admitan adición de información, porque si aquella afirmación fuera certera, no existiría una deducción propiamente dicha, sino una simple reproducción o repetición de lo planteado, puesto que el simple hecho de deducir implica una añadidura propia basada en la sana crítica (en este caso del jurista). 
Una ejemplificación pertinente a realizar, es el caso (hipotético) en que una señorita agrede físicamente a un anciano y le profiere golpes con fuerza abrupta hasta provocarle heridas graves. Si la supuesta víctima acude a fiscalía para denunciar el delito de intento de homicidio, le comenta su versión a fiscalía y fiscalía se limita a interpretar superficialmente lo percibido mediante aquel testimonio, iniciará el debido proceso sin tener una teoría del caso sólidamente sustentada, porque no dedujo en absoluto las posibles causas por las que la joven mantuvo ese comportamiento.

De la misma forma, sería sumamente injusto si el juez acepta ese testimonio y concede la razón al anciano porque presupone que, si la chica no acude voluntariamente a proporcionar su versión, es porque no quiere, porque no tiene razón, porque la razón solamente tiene aquel que acude ante el juez. Por consiguiente, es indispensable la añadidura de información a las premisas provistas, como en este caso, que en realidad la señorita actuó en legítima defensa al procurar evitar ser violada por el anciano, las versiones de ambas partes, los informes peritales, los testimonios, etc. La adición de información a base del criterio propio, puede generarse mediante el deductivismo, porque el conocimiento de los juristas adquirido tanto empírica como académicamente, tienen injerencia en dicho proceso.

Existen varias opciones para los agentes de derecho al momento de escoger el método e base del cual procederán, pero para el autor, el deductivismo es la alternativa que se utiliza con mayor asiduidad al momento de resolver casos, porque es necesario que se motive, justifique, razone y aplique adecuadamente sus saberes.

Es importante enfatizar que no solo el deductivismo importa en la emisión crítica de interpretaciones jurídicas de las normas y en la toma de decisiones por parte de los juristas; sino la lógica en su conjunto, porque el deductivismo, forma parte de la lógica, pero la lógica no es solo deductivismo, también existen otros recursos como la inferencia, analogía, entre otros. Entonces, se considera que la lógica jurídica es indispensable, aunque teleológicamente, pretende establecer conceptos universales para determinar reglas universalmente inteligibles; incluso podría señalarse que esa finalidad de la lógica es el intento de sustentar concepción del Derecho como una ciencia, porque utiliza los siguientes silogismos: 
1. Toda norma jurídica está compuesta por conceptos.

Los conceptos jurídicos tienen un significado respectivo que es único y universal.

Por lo tanto, Toda norma jurídica tiene un significado respectivo que es único y universal.

2. Toda ciencia tiene un significado respectivo que es único y universal.

Toda norma jurídica tiene un significado respectivo que es único y universal.

Entonces, toda norma jurídica es parte de una ciencia.

Así se demuestra la carente sustentación por parte de algunos autores que conciben al Derecho como ciencia, como por ejemplo García (2011) quien sostiene que: "En primer término, se señala que es de por sí equívoco individualizar con la misma palabra ("derecho") tanto al objeto de estudio (el derecho) como al estudio del objeto (es decir la ciencia)". Pero adoptar las ideas planteadas anteriormente, sería erróneo porque el derecho no puede considerarse como una ciencia, mucho menos el derecho hodierno. En la actualidad el Derecho depende de la lógica jurídica para su ejercicio empírico, pero no para imputarse como una ciencia.

Por consiguiente, se identifica que la deducción tiene mucha incidencia e importancia en la emisión crítica de interpretaciones jurídicas de las normas y en la toma de decisiones por parte de los juristas. Esto se debe a que el razonamiento de los abogados ineludiblemente les incita a deducir a base de escenarios jurídicos hipotéticos a los que pretenden respaldar o contrarrestar con la norma jurídica que según su sana crítica consideren pertinente. 


\section{DETERMINACIÓN DE LA RELEVANCIA QUE PRESENTA EL ANÁLISIS ECONÓMICO EN LA EFICACIA JURÍDICA A BASE DE LA PROPUESTA DE FRAGA (2016)}

Los juristas tienen injerencia exógena de factores que constituyen su contexto, pues el entorno político, económico, social y cultural en que se desenvuelven los abogados, consciente e inconscientemente influyen en su proceder como seres humanos pero también como profesionales, porque existe un proceso de alienación social que resulta ineludible para todas las personas indistintamente de la profesion que ejerzan.

La economía, además de incidir en el proceder de los juristas, también es la base para evidenciar lo eficaz que puede o no ser una norma. De esta manera Fraga (2016) destaca la relación entre la economía y la norma jurídica y señalan:

"El análisis económico contiene herramientas fundamentales para entender el comportamiento práctico de las instituciones jurídicas. Sin embargo, el análisis económico del derecho en su vertiente más tradicional, estaría trasladando al derecho los fallos metodológicos de la economía neoclásica."

Según este autor, el comportamiento práctico de las instituciones, es decir el desempeño de funciones de los órganos estatales, resulta inteligible desde la perspectiva económica porque permanentemente existe un trasfondo de índole económica, ya sea con tendencia de economía estatal o incluso intereses particulares de las máximas autoridades de esas instituciones. Es por esto que se afirma que mientras mejor economía exista en un país, mejor es la norma porque su eficacia es superior.

"El titular de derechos que administra individualmente sus derechos debe enfrentar todos los costos de manera individual, es decir, no está en la capacidad de agruparlos. Las negociaciones debe efectuarlas individualmente con cada uno de los usuarios potenciales de su obra. Esto implica tanto costos como riesgos jurídicos elevados para el titular de derechos" (Pérez, 2016).

Pérez, además, relaciona la economía al Derecho, en una propuesta sumamente distinta, porque hace referencia a los costos y riesgos jurídicos que implica administrar derechos de manera individual, que a su vez genera consecuencias a las que debe atenerse uno por uno. Sin embargo, esta postura, a pesar de no ser precisamente afín a la rela- 
ción que se trata en este documento, permite tener noción de otros puntos de vista en cuanto a la relación entre la normativa jurídica y la economía, al detonar su amplio alcance.

Pero, es importante recalcar que no solo el Derecho está influenciado por la economía, porque también el Derecho incide en la economía; es decir, existe injerencia mutua entre el Derecho y la economía. Es así como ciertos autores identifican la incidencia del Derecho en el ámbito económico y social al señalar:

"Desde un punto de vista jurídico, el juez es el aplicador e intérprete por excelencia, el encargado de convertir la ley en realidad. De esto se desprende claramente su responsabilidad en el funcionamiento del sistema económico y social. Sin embargo, debemos indicar que el juez, como cualquier individuo, también debe afrontar distorsiones cognitivas que podrían generar limitaciones en su actividad" (Méndez Reátegui, 2015).

Entonces, a base de la propuesta de Fraga se determina que la relevancia que presenta el análisis económico en la eficacia dinámica jurídica, es sumamente alta, porque la consecución de eficacia dinámica está orientada por los datos económicos que reflejan la óptima aplicación de la normativa jurídica. El Derecho y la economía son dos pilares de la sociedad, porque esta dualidad permite a las personas desenvolverse con recursos suficientes, pero con regulaciones que precautelan el orden social y la defensa de los derechos fundamentales que implican obligaciones imprescindibles. El Derecho es una construcción social, la sociedad tiene injerencia de la cultura, la cultura se moldea simultáneamente con la economía.

\section{ESTABLECIMIENTO DE UNA RELACIÓN ENTRE LA DE- DUCCIÓN Y LA EFICIENCIA AXIOLÓGICAMENTE ECONÓ- MICA EN LA COTIDIANEIDAD DE LOS AGENTES}

En primer lugar, es necesario aclarar el concepto de $<<$ eficiencia axiológicamente económica > y el motivo por el que se utiliza esa triada léxica. La eficiencia, desde esta perspectiva, se considera que la eficiencia es relativa e incluso subjetiva, puesto que la percepción de cada sociedad o individuo racional, varía respecto de lo que considere como eficiente o no, influenciado por sus propios preceptos. Sin embargo, la eficiencia, indistintamente de su relatividad, puede 
"medirse" de distintas formas en diversos aspectos de los seres humanos, como en su ámbito sociológico, cuando el orden de la sociedad es el óptimo, podría decirse que las medidas implementadas fueron eficientes; también en lo fisiológico, cuando las enfermedades controlables casi no tienen presencia en la sociedad en que se regulo de mejor manera todo lo relacionado a la salud; entre otros aspectos que permiten valorar cuan eficiente es la normativa jurídica.

"La eficiencia es un componente de la idea de justicia, pero no es el único criterio de justicia. Difícilmente podríamos calificar de justo un sistema totalmente ineficiente o una sociedad que despilfarra recursos que cubren necesidades básicas. Pero los criterios de eficiencia no son los únicos a tomar en cuenta para calificar un sistema como justo. Junto a la eficiencia, los derechos y objetivos colectivos ocupan un lugar sumamente importante. Un sistema institucional imprevisible e inseguro no puede ser calificado como justo. Pero un sistema muy ineficiente tampoco" (Calsamiglia, 1987).

La eficiencia constantemente se determina a base de valores, esos valores considerados como parámetros referenciales del ideal, pueden ser provistos por diferentes áreas, incluido el aspecto económico de la sociedad en que se pretende identificar cuan efectiva resulta una norma jurídica. Los valores son el objeto de estudio de la axiología, pero en este caso los valores son de índole económica. Es por este motivo que se parte del concepto de <<eficiencia axiológicamente económica >>.

En cambio, en cuanto a la eficacia del Derecho, un autor señala que:

"La aptitud del Derecho para desencadenar las transformaciones que se esperan de la vigencia de sus normas, depende de la dosis de voluntad y de interés con que el poder público las hace cumplir y consuma satisfactoriamente sus efectos. El poder que así actúa, se conduce al modo de un poder-función que - al contrario de la desnudez del poderfuerza-física o de la compulsión desmedida que refleja su rostro diabólico- persigue objetivos morales y sociales, cuyo alcance y conservación prueban su eficacia, y se caracteriza por la tenacidad con que va en busca de ellos y por la energía con que, una vez logrados, los defiende" (Ruiz, 1997).

De esta manera, Ruiz destaca la voluntad, interés e incluso fuerza de la administración pública, a los que considera factores claves para la eficiencia del Derecho, porque indica que la mutabilidad basada en la aplicación de la normativa jurídica emitida, depende de esos tres factores. 
Además, se considera que las normas y reglas de Derecho, son parte de un ordenamiento jurídico vigente en un determinado estado (aunque pueden existir ordenamientos casi idénticos). El estado en que se aplica la normativa jurídica emitida a través de la función legislativa del Estado, por parte de los agentes de Derecho en función del bienestar de los principales; consta de cuatro aspectos que se relacionan de manera simbiótica, el económico, jurídico, político y social.

El Estado utiliza la normativa jurídica para regular el comportamiento de la sociedad respecto a la economía y política estatales. Es indispensable recalcar que en la mayoría de ocasiones (por no decir en su totalidad), la efectividad de las reglas de Derecho emitidas se valora a base de la situación económica estatal, como por ejemplo, el ingreso per cápita que permite ponderar monetariamente el estilo de vida de cada ciudadano y consecuentemente el óptimo ejercicio de sus derechos que pretenden precautelar un adecuado estilo de vida para el ser humano.

Existen algunos autores que consideran a la economía como un eje del desarrollo social y consecuentemente del Derecho. Esto se evidencia al mencionar que:

"Sin embargo, la política social de este periodo siguió compensando los efectos perniciosos de las estrategias de política económica estatales y nacionales, que permiten la acumulación de capital entre las elites de poder económicas y políticas, pasando por alto los Derechos Económicos, Culturales y Sociales, sin la mínima intención de superar la pobreza. Existe una realidad que no podemos seguir negando, las mediciones de la pobreza lo fundamentan, pero es una realidad cercana a nosotros, observamos indigencia en las calles de las urbes, ausencia de infraestructura social básica, que hace precaria y más complicada la vida de las zonas rurales y algunas todavía son de difícil acceso." (Maldonado y Guerrero, 2016).

Para estos autores, también, existe una política económica estatal que solapa la hegemonía monetaria por parte de pocas personas que acumulan un poder elitista que, a su vez, obstaculiza la pretensión respecto de erradicar la pobreza. Todos los seres humanos tienen derecho a una vida digna en condiciones adecuadas para potenciar su desarrollo, pero la pobreza es la evidencia que denota la vulneración de los derechos fundamentales de toda persona, porque implícitamente incluye precariedad y un estilo de vida para nada digno. 
Del mismo modo, mencionan que los derechos económicos, culturales y sociales son desdeñados en la planificación proyectiva de la oligarquía. Este despojo, puede producir para Fraga, una eficiencia nula de las normas jurídicas emitidas, porque a pesar de su existencia positiva, en el ejercicio, es totalmente lo contrario.

Por lo tanto, se establece una relación imprescindible entre la deducción y la eficiencia axiológicamente económica en la cotidianeidad de los agentes, basada en la indispensabilidad de un proceso cognitivo de razonamiento, como la deducción, que le permita al agente en el ejercicio diario de su profesión, interpretar de manera crítica toda situación que se le presente y actuar a base de su propia iniciativa, al trascender de la mera aplicación de normas percibidas superficialmente.

\section{RELEVANCIA QUE PRESENTA TANTO LA PRAXEOLOGÍA COMO EL CONTEXTO DE LOS JURISTAS EN EL DERECHO HODIERNO}

Los juristas tienen injerencia exógena de factores que constituyen su contexto, pues el entorno político, económico, social y cultural en que se desenvuelven los abogados, consciente e inconscientemente influyen en su proceder como seres humanos pero también como profesionales, porque existe un proceso de alienación social que resulta ineludible para todas las personas indistintamente de la profesión que ejerzan. Por esta razón, se pretende determinar la relevancia que presenta tanto la praxeología como el contexto de los juristas en el derecho hodierno.

La terminología "derecho hodierno" es acuñada con el objetivo de denotar enfáticamente el escenario temporal en que se concibe al Derecho como una construcción praxeológica, que consiste en la actualidad, hoy en día, contemporáneamente, etc. Esta caracterización es pertinente, puesto que el Derecho en épocas distintas se soslaya a discursos que difieren entre sí según el contexto y consecuentemente el Derecho probablemente en tiempos pretéritos podía considerarse como un sistema más lógico que praxeológico. Sin embargo, hoy por hoy, o mejor dicho, el "Derecho hodierno", se considera mucho más praxeológico que lógico.

La praxeología es un factor primordial, porque en la praxis se expresa por completo la voluntad de los seres humanos, porque para que un su- 
jeto pueda crear Derecho, indiscutiblemente debe tener la capacidad de pensar y razonar. Pero, el pensar y el razonar son capacidades que la mayoría de seres humanos poseen de manera potencial; y, la potencia detona en acto solamente cuando el individuo racional, a base de su voluntad $\mathrm{y}$ al atravesar experimentaciones vitales, decide optar por desarrollar dichas capacidades y convertirlas en actividades, acciones, sucesos, hechos; porque el Derecho se crea solo cuando "el pensar" y "el razonar" se desarrollan en la realidad, de manera empírica, cuando la persona escoge utilizar sus capacidades para accionar con ayuda de ellas.

El contexto de los juristas, además de incidir en el proceder de los juristas, también es la base para evidenciar lo eficaz que puede o no ser una norma. De esta manera, algunos autores destacan la relación entre el contexto de los juristas y la norma jurídica y señalan:

"El titular de derechos que administra individualmente sus derechos debe enfrentar todos los costos de manera individual, es decir, no está en la capacidad de agruparlos. Las negociaciones debe efectuarlas individualmente con cada uno de los usuarios potenciales de su obra. Esto implica tanto costos como riesgos jurídicos elevados para el titular de derechos" (Pérez, 2016).

Pérez, relaciona el contexto económico de los juristas al Derecho, en una propuesta sumamente distinta, porque hace referencia a los costos y riesgos jurídicos que implica administrar derechos de manera individual, que a su vez genera consecuencias a las que debe atenerse uno por uno.

El Derecho es una construcción social, la sociedad tiene injerencia de la cultura, la cultura se moldea con simultáneamente a el contexto de los juristas. Por eso, se considera que el contexto económico, político, social y cultural es un factor exógeno de los juristas que tiene injerencia en ellos, porque los juristas ante todo, son seres humanos alienados a una determinada sociedad.

El modelo económico, el sistema político y el entorno cultural de una sociedad, inciden de manera directa e ineludible sobre las decisiones de los juristas, porque no será igual un abogado que se desarrolla en una sociedad capitalista, democrática, a un profesional del derecho que se desenvuelve en una sociedad socialista autoritarista. 
Por lo tanto, se determina que la relevancia que presenta tanto la praxeología como el contexto de los juristas en el Derecho, es sumamente alta. Hoy por hoy, o mejor dicho, el "Derecho hodierno", se considera como un cúmulo de preceptos normativos mucho más praxeológico que lógico; debido a que, en la praxis se expresa por completo la voluntad de los seres humanos, porque para crear Derecho, obviamente se necesita razonar y pensar, pero para poder pensar se necesita "querer hacer", decidir hacerlo, proponerse hacerlo y finalmente hacerlo gracias a la voluntad y al raciocinio lógico, pero esa expresión de voluntad se somete al contexto del jurista que incide en él al momento de decidirse a pensar, razonar, o no hacerlo. Solo así resulta posible la trascendencia de fases desde el "deber ser" al ser, existir, únicamente de este modo es posible la existencia del Derecho.

\section{CONCLUSIONES}

Se identifica que la deducción tiene injerencia importante en la emisión crítica de interpretaciones jurídicas de las normas y en la toma de decisiones por parte de los juristas. Esto se debe a que el razonamiento de los abogados ineludiblemente les incita a deducir a base de escenarios jurídicos hipotéticos a los que pretenden respaldar o contrarrestar con la norma jurídica que según su criterio considere pertinente. Se determina que la relevancia que presenta el análisis económico en la eficacia jurídica, es sumamente alta, porque la consecución de eficacia dinámica está orientada por los datos económicos que reflejan la óptima aplicación de la normativa jurídica. El Derecho y la economía son dos pilares de la sociedad, esta dualidad permite a las personas desenvolverse con recursos suficientes, pero con regulaciones que precautelan el orden social y la defensa de los derechos fundamentales que implican obligaciones imprescindibles. El Derecho es una construcción social, la sociedad tiene injerencia de la cultura, la cultura se moldea simultáneamente con la economía.

Se establece una relación imprescindible entre la deducción y la eficiencia axiológicamente económica en la cotidianeidad de los agentes, basada en la indispensabilidad de un proceso cognitivo de razonamiento, como la deducción, que le permita al agente en el ejercicio diario de su profesión, interpretar de manera crítica toda situación que se le presente y actuar a base de su propia iniciativa, al trascender de la mera aplicación de normas percibidas superficialmente. 
Se determina que la relevancia que presenta tanto la praxeología como el contexto de los juristas en el Derecho, es sumamente alta. Hoy por hoy, o mejor dicho, el "Derecho hodierno", se considera como un cúmulo de preceptos normativos mucho más praxeológico que lógico; debido a que, en la praxis se expresa por completo la voluntad de los seres humanos, porque para crear Derecho, obviamente se necesita razonar y pensar, pero para poder pensar se necesita "querer hacer", decidir hacerlo, proponerse hacerlo y finalmente hacerlo gracias a la voluntad y al raciocinio lógico, pero esa expresión de voluntad se somete al contexto del jurista que incide en él al momento de decidirse a pensar, razonar, o no hacerlo. Solo así resulta posible la trascendencia de fases desde el "deber ser" al ser, existir, únicamente de este modo es posible la existencia del Derecho.

Por lo tanto, se identifica que el deductivismo es sumamente útil en el ejercicio empírico del derecho hodierno que, constantemente pretende alcanzar la mayor eficacia posible, porque le permite a los juristas determinar una idea propia mediante un proceso de razonamiento basado en la extracción de esencialidades presuntamente verdaderas que, al ser comparadas generan un nivel de certeza mayor al corroborarse entre sí, o a su vez, permiten conocer las falacias cuando son de carácter antagónico. Entonces, la deducción es sumamente útil en la praxis del derecho hodierno, puesto que, permite realizar contrastaciones, comparaciones y extraer aspectos esenciales de toda información percibida sensorialmente; pero, no es suficiente para alcanzar el ideal eficaz de la norma, porque a pesar de su indispensabilidad, se requiere también de recursos racionales como la analogía crítica y la cognición teórica que se complementan entre sí y permiten tener una noción predictiva que simultáneamente incrementa el nivel de eficacia normativa.

\section{REFERENCIAS BIBLIOGRÁFICAS}

Benítez, J. M. (2010). Lógica, filosofía y educación. La lámpara de Diógenes, 11(20-21), 175-189. Obtenido de http://www.ldiogenes.buap. $\mathrm{mx} /$

Blancafort, A.C. (1987). Eficiencia y Derecho. (E. Díaz, E. Bulygin, \& Fiss Owen, Edits.) Doxa: Cuadernos de filosofía del derecho, 21(0214- 
8676), 267-281. Obtenido de https://dialnet.unirioja.es/servlet/articulo? codigo $=128707$

Bullard, A. (2009). La enseñanza del derecho: ¿cofradía o archicofradía?. Revista sobre enseñanza de derecho, 1-27.

Carrión, R. (207). Lógica jurídica: sobre el uso de la lógica en el razonamiento justificativo jurídico y la enseñanza del derecho positivo. Revista de la Facultad de Ciencias Jurídicas y Políticas (3), 235-251. Obtenido de http://perso.unifr.ch/derechopenal/assets/files/articulos/a_20080521_49.pdf

Casamilga, A. C. (1987). Eficiencia y Derecho. (E. Díaz, E. Bulygin, \& Fiss Owen, Edits.) Doxa: Cuadernos de filosofía del derecho, 21(02148676), 267-281. Obtenido de https://dialnet.unirioja.es/servlet/articulo? codigo $=128707$

Cordero, J. L. (2009). Lógica Y Sana Crítica. Revista Chilena de Derecho, 36 (1), 143 - 164. Obtenido de http://www.scielo.cl/scielo.php?script=sci_arttext\&pid=S0718-34372009000100007

Erandi, M. y Hilda, G. (2016). Aportaciones teóricas para la construcción de una política social. Obtenido de http://www.economiaysociedad.umich.mx/ojs_ecosoc/index.php/ecosoc/article/view/187/183

Fraga Lo Curto, L. (2016). Eficiencia dinámica y análisis praxeológico del derecho. Obtenidohttp://www.academia.edu/12072147/Eficiencia_dina_mica_y_ana_lisis_praxeo_logico_del_derecho

García, S. M. (2011). El derecho como ciencia. Invenio, 14(26), 13-38. Obtenido de http://www.ucel.edu.ar/index.php/component/content/ article/14-sample-data-articles/238-revista-academica

Méndez Reátegui, R. (2015). Una reflexión jurídico-económica e institucional. Revista del Instituto Colombiano de Derecho Procesal, 40(2346-3473). Obtenido de http://publicacionesicdp.com/index. php/Revistas-icdp/article/view/9/html

Moretti, A. (2016). La lógica y la trama de las cosas. Ideas y Valores, 65(161), 5-22. Obtenido de http://revistas.unal.edu.co/index.php/idval 
Pérez, A. M. (2016). Análisis económico del derecho de autor. La propiedad Inmaterial , 45-56. Obtenido de http://revistas.uexternado.edu. co/index.php/propin/article/view/2995/2639

Ruiz, M. M. (1997). Eficacia y efectividad del derecho. Estudios de Deusto, 45(0423-4847), 120-124. Obtenido de http://revista-estudios.revistas.deusto.es/article/view/608/770

Sunstein, C. R. (2012). Análisis Conductual del Derecho. Revista Advocatus Nueva Época, 71-86.

Villalibre Fernández, V. (2012). Confluencia del Derecho a la Tutela Judicial Efectiva con el concepto de «investigación oficial eficaz». Foro. Revista de Ciencias Jurídicas y Sociales, Nueva Época(2255-5285), 29-86. Obtenido de http://revistas.ucm.es/index.php/FORO/article/ view/39582/38089

Zorzi, J. P. (2005). Razonamiento Jurídico y toma de decisión. Breves notas acerca de la influencia de la racionalidad y la irracionalidad en la decisión judicial. Universitas, Revista de Filosofía, Derecho y Política, 3(1698-7950), 3-22.

Recibido: 08/09/2017

Aceptado: 5/05/2018

Valeria Freire Yacelga: Investigadora Jurídica TAXFIRM

Correo electrónico: valefreire98@hotmail.com 